\title{
Efeito do nitrogênio em genótipos de feijão cultivados em várzea úmida irrigada do Estado do Tocantins
}

\section{Effect of nitrogen in bean genotypes grown in irrigated lowland of the State of Tocantins}

\author{
Sérgio Alves de Sousa ${ }^{1}$, Joedna Silva ${ }^{1}$, José Luiz Venâncio ${ }^{2}$, Taynar Coelho de Oliveira, \\ Hélio Bandeira Barros ${ }^{1}$ e Rodrigo Ribeiro Fidelis ${ }^{*}$ \\ ${ }^{1}$ Departamento de Agronomia; Universidade Federal do Tocantins; 77402-970; Gurupi - TO - Brasil. \\ ${ }^{2}$ COPERJAVA; 77470-000; Formoso do Araguaia - TO - Brasil.
}

\begin{abstract}
The bean crop has a major socioeconomic importance for Brazil and the nitrogen fertilization is one of the most limiting factors. The aim of this paper was to assess the effect of nitrogen fertilization over common bean genotypes grown in an irrigated lowland field at State of Tocantins. The study was conducted throughout two trials (high and low nitrogen), both in a completely randomized blocks design, being essayed 25 genotypes in three replications. The evaluated characteristics were height of first pod insertion, plant height, number of pods per plant, number of grains per pod, one hundred grains mass and grain yield. The evaluated genotypes suit to mechanical harvest and presented positive response to nitrogen fertilization. The genotype CNFC-10467 standed out and presented potential to be grown in irrigated lowland from State of Tocantins.
\end{abstract}

Key-words: Phaseolus vulgaris, mineral stress, subirrigation

\section{INTRODUÇÃO}

Originário das Américas, o feijoeiro (Phaseolus vulgaris $L$.) após domesticação teve seu cultivo expandido por todo o mundo, tornando-se a espécie mais cultivada dentro do gênero Phaseolus (Singh, 1982; Santos e Gavilanes, 2006). Trata-se de uma leguminosa com grande importância socioeconômica, pelo fato do feijão ser componente fundamental da dieta do brasileiro como rica fonte de proteínas, vitaminas, carboidratos, ferro, além de ser uma cultura com grande geração de empregos, devido alta demanda de mão-de-obra durante todo o seu ciclo (Fageria,1998; Borém e Carneiro, 2006; Binotti et al., 2009).

O Brasil é considerado o maior produtor de feijão do mundo, porém não se tornou auto-suficiente, pois ainda há a necessidade de importação para suprir a demanda interna (Mechi et al., 2005). De acordo com estimativas da Conab (2011), a produtividade média nacional e do estado do Tocantins são de 885 e $1.554 \quad \mathrm{~kg}^{-h^{-1}}{ }^{-1}$, respectivamente. Porém em trabalhos de pesquisa realizados no país e no Tocantins, constataram-se produtividades superiores aos $3.000 \mathrm{~kg} \mathrm{ha}^{-1}$ (Lemos et al., 2004; Salgado et al., 2011; Salgado, 2011), o que significa possibilidade e potencial para incrementos nos rendimentos, desde que adotadas tecnologias adequadas (Fageria et al., 1996).

Estudos mostram que o Tocantins apresenta uma enorme capacidade produtiva para o cultivo de feijão na entressafra (Salgado et al., 2011). Os cultivos em várzeas do Estado do Tocantins têm demonstrado potencial, tendo sido obtidos rendimentos superiores a três toneladas por hectare, com custo de produção muito baixo. Este potencial também caracteriza-se pela localização estratégica em relação aos mananciais hídricos e mercado consumidor (Aidar e Kuthcouski, 2008). 
Segundo Fageria et al. (1996), as baixas produtividades obtidas pela cultura do feijoeiro podem ser explicadas pela enorme susceptibilidade às variações climáticas, incidências de pragas e doenças, pesquisa incipiente em melhoramento genético, instabilidade na fixação de $\mathrm{N}_{2}$ e uso inadequado da adubação mineral. Desta forma, o uso adequado da adubação dentre outros fatores, podem contribuir para incrementos nos rendimentos.

Em condições de várzea o nitrogênio é considerado um dos nutrientes mais limitantes, ficando atrás somente do fósforo, porém em termos de absorção é o nutriente absorvido em maior quantidade pelo feijoeiro sendo necessário de 23 a $27 \mathrm{~kg} \cdot \mathrm{ha}^{-1}$ de $\mathrm{N}$ para a produção de uma tonelada de grãos (Fageria et al., 1996; Fageria e Santos, 1998).

O nitrogênio é responsável pelo aumento da área foliar, aumentando a eficiência de interceptação da radiação solar, a taxa fotossintética e conseqüentemente a produção (Fageria e Baligar, 2005). Devido à facilidade de perdas desse nutriente por diversos processos (lixiviação, desnitrificação e volatilização) o uso racional é de fundamental importância para ganhos de rendimento, redução nos custos de produção e riscos de poluição ambiental (Fageria et al., 2003; Sant'Ana et al., 2010; Cardoso et al., 2011).

Vários são os estudos com relatos do efeito da adubação nitrogenada em diversas culturas como milho, arroz e feijão (Santos et al., 2003; Fidelis et al., 2010; Kischel et al., 2011; Salgado et al., 2011), assim como o agrupamento dos genótipos de acordo com a capacidade destes de resposta e utilização do nitrogênio. Porém os estudos com o efeito da adubação nitrogenada na cultura do feijão em condições de várzea irrigada do estado do Tocantins ainda são bastante incipientes.

Diante deste contexto, objetivou-se com este estudo avaliar o efeito da adubação nitrogenada em genótipos de feijão comum cultivados em solos de várzea irrigada do Estado do Tocantins.

\section{MATERIAL E MÉTODOS}

Os experimentos foram conduzidos no município de Formoso do Araguaia-TO, em solo tipo Gleissolo (Embrapa, 2006), de várzea irrigada do módulo I-14 da COPERJAVA (Cooperativa Mista do Vale do Araguaia), nas coordenadas geográficas $11^{\circ} 48^{\prime} \mathrm{S}$ e $49^{\circ} 37^{\prime} \mathrm{W}$, a $227 \mathrm{~m}$ de altitude.
Anterior a implantação do experimento foram coletadas amostras de solo na camada de $0-20 \mathrm{~cm}$ de profundidade para análise química e física do solo, obtendo os seguintes resultados: $\mathrm{pH} \mathrm{em} \mathrm{H}_{2} \mathrm{O}$ $=5,44 ;$ M.O $\left(\mathrm{g} \mathrm{dm}^{-3}\right)=71,71 ; \mathrm{P}\left(\mathrm{Melich}^{-1}\right)=9,61$; $\mathrm{Ca}=3,07 \mathrm{cmol}_{\mathrm{c}} \mathrm{dm}^{-3} ; \mathrm{Mg}=1,12 \mathrm{cmol}_{\mathrm{c}} \mathrm{dm}^{-3} ; \mathrm{H}+\mathrm{Al}$ $=4,36 \mathrm{cmol}_{\mathrm{c}} \mathrm{dm}^{-3} ; \mathrm{K}=0,03 \mathrm{cmol}_{\mathrm{c}} \mathrm{dm}^{-3} ; \mathrm{SB}=4,22$ $\mathrm{cmol}_{\mathrm{c}} \mathrm{dm}^{-3} ; 547,35 \mathrm{~g} \mathrm{~kg}^{-1}$ de areia; $166,7 \mathrm{~g} \mathrm{~kg}^{-1}$ de sílte e $285,99 \mathrm{~g} \mathrm{~kg}^{-1}$ de argila.

A avaliação dos genótipos foi conduzida em dois experimentos simultâneos (sob baixo e alto nível de nitrogênio). Em ambos, o delineamento experimental utilizado foi o de blocos ao acaso com três repetições. Cada unidade experimental foi constituída por quatro linhas de $5,0 \mathrm{~m}$ de comprimento, espaçadas de $0,45 \mathrm{~cm}$. Como área útil foram utilizadas as duas linhas centrais desprezando-se as duas linhas laterais e $0,5 \mathrm{~m}$ das extremidades das duas linhas centrais, ficando com linhas de 4,0m de comprimento e área útil de $3,6 \mathrm{~m}^{2}$.

Foram utilizadas quatro linhagens (CNFC-10406, CNFC-10467, CNFC-10470 e VC-3) e vinte e um cultivares (BRS-Aporé, BRS-Esplendor, BRSGrafite, BRS-Horizonte, IAC-Alvorada, IACDiplomata, IAC-Eté, IAC-Galante, IAC-Una, IPR139, IPR-Chopim, IPR-Colibri, IPR-Corujinha, IPR-Gralha, IPR-Saracura, IPR-Tiziu, BRSMarfim, BRS-Majestoso, Uirapuru e Safira).

$\mathrm{O}$ preparo do solo foi realizado de forma convencional, ou seja, com uma aração e duas gradagens. A semeadura foi realizada no dia 4 de junho de 2011. O plantio foi realizado visando obter estande final de 12 plantas por metro linear. A adubação de semeadura foi realizada no sulco de plantio com base nos resultados da análise química e física do solo, sendo aplicados 500 $\mathrm{kg} \cdot \mathrm{ha}^{-1}$ do adubo formulado $0-16-16+6 \% \mathrm{~S}+$ micro. A adubação de cobertura foi realizada aplicandose $120 \mathrm{~kg} \mathrm{ha}^{-1}$, aos 20 dias após a emergência das plântulas, na forma de sulfato de amônio. (Rosolem e Marubayashi, 1994). Na condição de baixo nível de nutriente não foi realizada adubação nitrogenada, pois a área de acordo com estimativas considerando uma média de $5 \%$ de mineralização do N-orgânico por ano (Camargo et al., 2008), encontrava-se com níveis adequados para simulação dessa condição ( $35 \mathrm{~kg} \cdot \mathrm{ha}^{-1}$ de $\left.\mathrm{N}\right)$.

Foi realizado o tratamento de sementes com aplicação de $300 \mathrm{ml} / 100 \mathrm{~kg}$ de sementes do fungicida pertencente ao grupo químico benzimidazol e do inseticida pertencente ao grupo químico imidacloprido+tiodicarbe. 
Durante a condução do experimento para o controle das plantas daninhas (Ciperáceas) foram aplicados 1,2 L.ha ${ }^{-1}$ de um herbicida pertencente ao grupo químico benzotiadiazinonan. Para o controle dos insetos (Diabrotica speciosa) foi realizada a aplicação de $0,6 \mathrm{~L} . h a^{-1}$ de um inseticida pertencente ao grupo químico organofosforado e para o controle de doença (Sclerotinia sclerotiorum) foi realizado uma aplicação de 70 g.p.c de um fungicida pertencente ao grupo químico benzimidazol.

Para avaliação das características fitotécnicas, amostraram-se cinco plantas aleatórias e representativas. As características avaliadas foram altura da planta - medindo-se do colo da planta até o final da haste principal; altura de inserção de primeira vagem - medindo-se do solo até o ponto de inserção da primeira vagem; número de vagens por planta - sendo obtido pela contagem do número total de vagens por planta; número de grãos por vagem - obtido através do número total de grãos e dividindo o resultado pelo número total de vagens; massa de cem grãos - tomando-se cem grãos da área útil, pesando e corrigindo a umidade para $13 \%$ e produtividade de grãos - feito através do peso de grãos da área útil em quilogramas, com correção para $13 \%$ de umidade transformando os dados para kg.ha ${ }^{-1}$.

Os dados experimentais foram submetidos a análise individual e conjunta de variância, com aplicação do teste F. A análise conjunta foi realizada sob condições de homogeneidade das variâncias residuais. Para as comparações entre as médias de tratamentos (genótipos), foi utilizado o teste Scott-knott e para comparações entre ambientes foi utilizado o teste Tukey, a $5 \%$ de probabilidade de erro, o que foi feito, utilizando-se o aplicativo computacional SISVAR (Ferreira, 2008).

\section{RESULTADOS E DISCUSSÃO}

$\mathrm{Na}$ Tabela 1 são apresentados os resultados da análise de variância, onde para a interação genótipo versus ambiente foi observado significância ao nível de 1\% para as características número de grãos por vagem, massa de cem grãos e produtividade de grãos e ao nível de $5 \%$ para a característica de número de vagens por planta, caracterizando interdependência dos fatores, ou seja, os níveis de $\mathrm{N}$ influenciam de forma diferenciada a expressão dos genótipos estudados. Desta forma, realizou-se o desdobramento de um fator dentro do outro. Para as características altura de plantas e altura de inserção de primeira vagem não foi observada significância para a interação genótipo versus ambiente, o que caracteriza independência dos fatores, não havendo influência dos níveis de $\mathrm{N}$ de forma diferenciada nos genótipos, sendo desta forma, estudados isoladamente.

Ainda na Tabela 1, observa-se significância para todas as características estudadas no fator genótipo, o que também ocorreu no fator ambiente, exceto para a característica de altura de inserção de primeira vagem.

Foram observados baixos coeficientes de variação (CV) para a maioria das características, excetuando para número de vagens por planta e produtividade de grãos $(23,32 \%$ e $30,20 \%)$, respectivamente (Tabela 1). Salgado et al. (2011), obtiveram elevado CV para número de vagens por planta $(24,15 \%)$ e baixo CV para produtividade $(13,8 \%)$. Salgado (2011) avaliando o comportamento de genótipos de feijoeiro no sul do Tocantins em condições de estresse de nitrogênio obteve CV elevado para as mesmas características observadas no presente estudo. Estes elevados coeficientes de variação não são considerados inadequados para ensaios em condições de estresse (Blum, 1988). Santos et al. (1998), avaliando populações de milho em condições de estresse de nitrogênio também obtiveram coeficientes de variação elevados, sendo os valores de $22,3 \%(\mathrm{~N}+)$ e 23,4\% (N-). Também na cultura do milho (Zea mays $L$.) em condições de estresse mineral, Fidelis et al. (2009), observaram CV de $42,8 \%$ para a característica de produtividade de grãos. 
Tabela 1. Resumo da análise de variância das médias de altura de planta (AP), altura de inserção da primeira vagem (IPV), número de vagem por planta (NVP), número de grãos por vagem (NGV), massa de cem grãos (MCG) e produtividade de grãos (PROD), de vinte e cinco genótipos de feijão comum cultivados em área de várzea irrigada do Estado do Tocantins, na entressafra de 2011.

\begin{tabular}{lccccccc}
\hline \multirow{2}{*}{ FV } & \multirow{2}{*}{ GL } & \multicolumn{5}{c}{ QUADRADO MÉDIO } \\
\cline { 3 - 7 } & & AP & AIV & NVP & NGV & MCG & PROD \\
\hline Blocos/Amb & 4 & $303,59^{*}$ & $38,68^{\text {ns }}$ & $2,20^{\text {ns }}$ & $0,71^{\text {ns }}$ & $17,26^{* *}$ & $69895,56^{*}$ \\
Genótipos (G) & 24 & $356,46^{* *}$ & $32,23^{*}$ & $14,97^{* *}$ & $1,33^{* *}$ & $30,18^{* *}$ & $54030,24^{* *}$ \\
Ambiente (A) & 1 & $7959,95^{* *}$ & $0,0024^{\text {ns }}$ & $382,01^{* *}$ & $7,37 * *$ & $766,95^{* *}$ & $14863458,32^{* *}$ \\
G x A & 24 & $127,39^{\text {ns }}$ & $16,18^{\text {ns }}$ & $4,17^{*}$ & $1,47^{* *}$ & $12,92^{* *}$ & $84110,96^{* *}$ \\
Resíduos & 96 & 116,67 & 16,70 & 2,13 & 0,65 & 4,37 & 23504,61 \\
\hline \multicolumn{1}{c}{ Média Geral } & & 70,65 & 22,74 & 6,26 & 4,13 & 21,80 & 507,66 \\
\hline CV(\%) & & 15,29 & 17,97 & 23,32 & 19,60 & 9,59 & 30,20 \\
\hline
\end{tabular}

Na Tabela 2 são apresentadas as médias de altura de planta e altura de inserção da primeira vagem para os ambientes de baixa e alta dose de nitrogênio

Quanto à altura de plantas, as maiores alturas foram observadas em condições de alto nitrogênio, com média de 77,94 cm (Tabela 2). Com relação aos genótipos, o cultivar BRS-Aporé apresentou a maior altura $(85,68 \mathrm{~cm})$, apesar de não diferir significativamente dos genótipos que apresentaram média superior a $70,38 \mathrm{~cm}$.

Numa avaliação de 14 genótipos de feijão comum em terras altas, Salgado et al. (2011) observaram variação de 67 a $108 \mathrm{~cm}$ de altura quando aplicados 80 kg.ha ${ }^{-1}$ de nitrogênio. Já em outro estudo avaliando o comportamento de 12 genótipos de feijoeiro em terras altas, Salgado (2011) observou menor variação $(49,6$ a 76,4). Ambos os estudos corroboram com os resultados obtidos neste trabalho. De acordo com Simone et al. (1992), alturas superiores a $50 \mathrm{~cm}$ são favoráveis a colheita mecanizada, porém plantas muito altas também são mais suscetíveis ao acamamento, o que impossibilita a colheita mecanizada. As alturas apresentadas neste trabalho demonstram potencialidade para colheita mecanizada.

Quanto à altura de inserção da primeira vagem, observou-se que o incremento de $\mathrm{N}$ não resultou em aumento da AIV, sendo observado nos dois ambientes médias superiores a $22,74 \mathrm{~cm}$. O grupo com as maiores médias de altura de inserção da primeira vagem foi composto por 13 genótipos, com médias superiores a $23,13 \mathrm{~cm}$ (Tabela 2).

Tabela 2. Médias das características altura de planta (AP) e altura de inserção da primeira vagem (AIV) de 25 genótipos de feijão comum cultivados em área de várzea irrigada do Estado do Tocantins, na entressafra de 2011.

\begin{tabular}{lcccccc}
\hline \multirow{2}{*}{ Genótipo } & \multicolumn{3}{c}{ AP $(\mathrm{cm})$} & & AIV $(\mathrm{cm})$ \\
\cline { 2 - 6 } & Baixo N & Alto N & Média & Baixo N & Alto N & Média \\
\hline CNFC-10467 & 63,26 & 81,10 & $72,18 \mathrm{a}$ & 21,53 & 22,66 & $22,10 \mathrm{~b}$ \\
IAC-Una & 60,60 & 68,73 & $64,66 \mathrm{~b}$ & 18,80 & 23,33 & $21,06 \mathrm{~b}$ \\
CNFC-10406 & 64,73 & 88,00 & $76,36 \mathrm{a}$ & 19,80 & 22,60 & $21,20 \mathrm{~b}$ \\
BRS-Esplendor & 58,20 & 78,66 & $68,43 \mathrm{~b}$ & 20,73 & 22,33 & $21,53 \mathrm{~b}$ \\
IPR-Chopin & 65,73 & 60,13 & $62,93 \mathrm{~b}$ & 25,80 & 21,80 & $23,80 \mathrm{a}$ \\
BRS-Aporé & 78,70 & 92,66 & $85,68 \mathrm{a}$ & 25,90 & 21,33 & $23,61 \mathrm{a}$ \\
BRS-Horizonte & 55,26 & 66,06 & $60,66 \mathrm{~b}$ & 22,93 & 23,33 & $23,13 \mathrm{a}$ \\
IAC-Galante & 58,80 & 88,00 & $73,40 \mathrm{a}$ & 22,93 & 24,53 & $23,73 \mathrm{a}$ \\
BRS-Majestoso & 64,66 & 77,20 & $70,93 \mathrm{a}$ & 21,26 & 23,66 & $22,46 \mathrm{~b}$ \\
BRS-Grafite & 58,66 & 78,93 & $68,80 \mathrm{~b}$ & 23,40 & 29,33 & $26,36 \mathrm{a}$ \\
VC3 & 68,20 & 73,13 & $70,66 \mathrm{a}$ & 20,66 & 19,73 & $20,20 \mathrm{~b}$ \\
Uirapuru & 51,06 & 75,53 & $63,30 \mathrm{~b}$ & 23,06 & 24,53 & $23,80 \mathrm{a}$ \\
BRS-Marfim & 48,80 & 76,66 & $62,73 \mathrm{~b}$ & 19,33 & 18,73 & $19,03 \mathrm{~b}$ \\
IPR-Colibri & 46,20 & 58,26 & $52,23 \mathrm{~b}$ & 16,46 & 20,40 & $18,43 \mathrm{~b}$ \\
\hline
\end{tabular}




\begin{tabular}{lcccccc}
\hline IPR-Saracura & 72,53 & 82,86 & $77,70 \mathrm{a}$ & 23,00 & 19,13 & $21,06 \mathrm{~b}$ \\
IAC-Eté & 68,73 & 91,13 & $79,93 \mathrm{a}$ & 24,73 & 26,46 & $25,60 \mathrm{a}$ \\
Safira & 72,93 & 82,13 & $77,53 \mathrm{a}$ & 27,66 & 24,20 & $25,93 \mathrm{a}$ \\
IPR-Corujinha & 52,80 & 70,66 & $61,73 \mathrm{~b}$ & 17,40 & 18,93 & $18,16 \mathrm{~b}$ \\
CNFC-10470 & 64,66 & 77,60 & $71,13 \mathrm{a}$ & 25,53 & 21,86 & $23,70 \mathrm{a}$ \\
IAC-Alvorada & 69,26 & 88,13 & $78,70 \mathrm{a}$ & 20,46 & 22,80 & $21,63 \mathrm{~b}$ \\
IPR-Tiziu & 73,46 & 73,53 & $73,50 \mathrm{a}$ & 27,73 & 21,53 & $24,63 \mathrm{a}$ \\
IPR-139 & 84,33 & 79,86 & $82,10 \mathrm{a}$ & 25,60 & 22,60 & $24,10 \mathrm{a}$ \\
IAC-Diplomata & 63,26 & 77,50 & $70,38 \mathrm{a}$ & 26,80 & 25,70 & $26,25 \mathrm{a}$ \\
Pérola & 61,80 & 86,73 & $74,26 \mathrm{a}$ & 20,53 & 24,33 & $22,43 \mathrm{~b}$ \\
IPR-Gralha & 57,60 & 75,26 & $66,43 \mathrm{~b}$ & 26,46 & 22,86 & $24,66 \mathrm{a}$ \\
\hline \multicolumn{1}{c}{ Média } & $63,37 \mathrm{~B}$ & $77,94 \mathrm{~A}$ & \multicolumn{5}{c}{$22,74 \mathrm{~A}$} & $22,75 \mathrm{~A}$ & \\
\hline
\end{tabular}

Médias seguidas de mesma letra minúscula na coluna não diferem entre si pelo teste Scott-Knott e maiúscula na linha pelo teste Tukey, ambos a $5 \%$ de probabilidade.

Os valores de altura de inserção da primeira vagem encontradas nesse estudo demonstram aptidão de todos os genótipos para a prática da colheita mecanizada (Silveira, 1991). Além do benefício da viabilização da colheita mecanizada, o menor contato das vagens com o solo reduz a contaminação por patógenos de solo, favorecendo a qualidade fitossanitária das vagens (Salgado, 2011).

Para a característica de número de vagens por planta (Tabela 3), observou-se que o genótipo IPR-Corujinha destacou-se por apresentar média superior tanto em condições de baixa dose de nitrogênio $(9,55)$ como em condições de alta dose de nitrogênio $(12,07)$, embora neste ambiente não tenha diferido do genótipo IPR-Chopin que apresentou a maior média (Tabela 3). Estes valores corroboram com as médias obtidas por Lemos et al. (2004) e Salgado (2011), sendo inferiores aos valores obtidos por Salgado et al. (2011).

$\mathrm{O}$ ambiente de alta dose de nitrogênio obteve as maiores médias de número de vagens por planta comparado ao ambiente de baixa dose, com médias de 4,66 e 7,85 vagens por planta, respectivamente. Com o acréscimo da adubação nitrogenada, 14 genótipos apresentaram resposta positiva com incrementos variando de 2,97 a 7,54 vagens por planta.

Quanto ao número de grãos por vagem em condições de estresse de nitrogênio, o genótipo
IPR-Tiziu apresentou o maior valor $(5,83)$, não diferindo significativamente dos genótipos IACUna, Uirapuru e Safira, que apresentaram 5,29, 4,78 e 4,63, respectivamente (Tabela 3). Estes valores são semelhantes aos obtidos por Lemos et al. (2004) em condições normais de cultivo. Embora tenha apresentado o maior número de grãos por vagem em condições de déficit, o genótipo IPR-Tiziu não apresentou resposta positiva ao acréscimo da adubação nitrogenada. Salgado (2011) também observou decréscimo no número de grãos por vagem em alguns genótipos quando submetidos a alta dose de nitrogênio.

Em condições de alta dose de nitrogênio, os genótipos BRS-Majestoso e IPR-Saracura obtiveram os maiores valores de grãos por vagem, porém não diferiram significativamente dos demais genótipos. Somente cinco genótipos apresentaram resposta positiva ao acréscimo de nitrogênio, sendo eles, BRS-Aporé, BRSMajestoso, VC3, BRS-Marfim e IPR-Saracura. Salgado et al. (2011) observaram valores de número de grãos por vagem superiores aos encontrados neste trabalho, com variação de 7,48 a 14,46 grãos por vagem. Salgado (2011) encontrou valores semelhantes aos apresentados no presente trabalho, com variação de 2,7 a 5,4 grãos por vagem. 
Tabela 3. Médias das características número de vagens por planta (NVP) e número de grãos por vagem (NGV) de 25 genótipos de feijão comum cultivados em área de várzea irrigada do Estado do Tocantins, na entressafra de 2011

\begin{tabular}{|c|c|c|c|c|c|c|}
\hline \multirow{2}{*}{ Genótipo } & \multicolumn{3}{|c|}{ NVP } & \multicolumn{3}{|c|}{ NGV } \\
\hline & Baixo N & Alto N & Média & Baixo N & Alto N & Média \\
\hline CNFC-10467 & $4,97 \mathrm{cA}$ & $6,71 \mathrm{dA}$ & 5,84 & $3,89 \mathrm{bA}$ & $3,73 \mathrm{aA}$ & 3,81 \\
\hline IAC-Una & $6,21 \mathrm{bA}$ & $8,53 \mathrm{cA}$ & 7,37 & $5,29 \mathrm{aA}$ & $4,26 \mathrm{aA}$ & 4,77 \\
\hline CNFC-10406 & $4,47 \mathrm{cB}$ & $9,05 \mathrm{bA}$ & 6,76 & $3,87 \mathrm{bA}$ & $3,90 \mathrm{aA}$ & 3,88 \\
\hline BRS-Esplendor & $4,42 \mathrm{cB}$ & $7,39 \mathrm{cA}$ & 5,91 & $4,18 \mathrm{bA}$ & $4,69 \mathrm{aA}$ & 4,44 \\
\hline IPR-Chopin & $5,14 \mathrm{cB}$ & $12,68 \mathrm{aA}$ & 8,91 & $4,06 \mathrm{bA}$ & $4,90 \mathrm{aA}$ & 4,48 \\
\hline BRS-Aporé & $4,53 \mathrm{cB}$ & $7,78 \mathrm{cA}$ & 6,16 & $2,65 \mathrm{bB}$ & 4,61 aA & 3,63 \\
\hline BR-Horizonte & $3,15 \mathrm{cB}$ & $6,15 \mathrm{dA}$ & 4,65 & $4,25 \mathrm{bA}$ & $4,21 \mathrm{aA}$ & 4,23 \\
\hline IAC-Galante & $4,47 \mathrm{cB}$ & $9,82 \mathrm{bA}$ & 7,15 & $3,70 \mathrm{bA}$ & $3,94 \mathrm{aA}$ & 3,82 \\
\hline BRS-Majestoso & $4,16 \mathrm{cA}$ & $5,82 \mathrm{dA}$ & 4,99 & $3,53 \mathrm{bB}$ & $5,86 \mathrm{aA}$ & 4,69 \\
\hline BRS-Grafite & $4,14 \mathrm{cB}$ & $8,36 \mathrm{cA}$ & 6,25 & $4,19 \mathrm{bA}$ & $4,75 \mathrm{aA}$ & 4,47 \\
\hline VC3 & $4,95 \mathrm{cA}$ & $6,65 \mathrm{dA}$ & 5,80 & $3,01 \mathrm{bB}$ & $4,51 \mathrm{aA}$ & 3,76 \\
\hline Uirapuru & $3,52 \mathrm{cA}$ & $5,68 \mathrm{dA}$ & 4,60 & $4,78 \mathrm{aA}$ & $4,72 \mathrm{aA}$ & 4,75 \\
\hline BRS-Marfim & $3,59 \mathrm{cB}$ & $6,16 \mathrm{dA}$ & 4,87 & $2,29 \mathrm{bB}$ & $4,13 \mathrm{aA}$ & 3,21 \\
\hline IPR-Colibri & $6,76 \mathrm{bB}$ & $10,60 \mathrm{bA}$ & 8,68 & $3,82 \mathrm{bA}$ & $3,75 \mathrm{aA}$ & 3,78 \\
\hline IPR-Saracura & $4,77 \mathrm{cA}$ & $6,35 \mathrm{dA}$ & 5,56 & $3,95 \mathrm{bB}$ & $5,99 \mathrm{aA}$ & 4,97 \\
\hline IAC-Eté & $3,49 \mathrm{cA}$ & $5,56 \mathrm{dA}$ & 4,52 & $3,80 \mathrm{bA}$ & $4,32 \mathrm{aA}$ & 4,06 \\
\hline Safira & $2,83 \mathrm{cA}$ & $4,71 \mathrm{dA}$ & 3,77 & $4,63 \mathrm{aA}$ & $4,65 \mathrm{aA}$ & 4,64 \\
\hline IPR-Corujinha & $9,55 \mathrm{aB}$ & $12,07 \mathrm{aA}$ & 10,81 & $3,54 \mathrm{bA}$ & $442 \mathrm{aA}$ & 3,98 \\
\hline CNFC-10470 & $5,28 \mathrm{cA}$ & $7,37 \mathrm{cA}$ & 6,32 & $3,57 \mathrm{bA}$ & $4,40 \mathrm{aA}$ & 3,98 \\
\hline IAC Alvorada & $3,65 \mathrm{cB}$ & $7,92 \mathrm{cA}$ & 5,78 & $3,93 \mathrm{bA}$ & $4,08 \mathrm{aA}$ & 4,00 \\
\hline IPR Tiziu & $3,67 \mathrm{cB}$ & $9,08 \mathrm{bA}$ & 6,37 & $5,83 \mathrm{aA}$ & $3,60 \mathrm{aB}$ & 4,72 \\
\hline IPR 139 & $4,49 \mathrm{cB}$ & $9,86 \mathrm{bA}$ & 7,17 & $3,14 \mathrm{bA}$ & $3,28 \mathrm{aA}$ & 3,21 \\
\hline IAC Diplomata & $2,85 \mathrm{cB}$ & $8,19 \mathrm{cA}$ & 5,52 & $3,80 \mathrm{bA}$ & $4,21 \mathrm{aA}$ & 4,00 \\
\hline Pérola & $4,42 \mathrm{cA}$ & $5,68 \mathrm{dA}$ & 5,05 & $4,22 \mathrm{bA}$ & $3,97 \mathrm{aA}$ & 4,09 \\
\hline IPR Gralha & 7,09 bA & $8,17 \mathrm{cA}$ & 7,63 & $3,89 \mathrm{bA}$ & $4,02 \mathrm{aA}$ & 3,95 \\
\hline Média & 4,66 & 7,85 & & 3,91 & 4,35 & \\
\hline
\end{tabular}

Médias seguidas de mesma letra minúscula na coluna não diferem entre si pelo teste Scott-Knott e maiúscula na linha pelo teste Tukey, ambos a 5\% de probabilidade.

Para a característica de massa de cem grãos houve a formação de dois grupos de genótipos nas condições de baixo nitrogênio. Um grupo composto de 16 genótipos que apresentaram as maiores massas, variando de 19,33 a 23,48 gramas, sendo o genótipo IPR-139 o que apresentou a maior massa (Tabela 4). Para as condições de alta dose de nitrogênio houve a formação de três grupos estatísticos, sendo o grupo de maiores massas composto por 13 genótipos com variação de 24,14 a 27,61 gramas. Lemos et al. (2004) em estudo com adubação nitrogenada em duas safras na época das águas observaram maiores valores de massas para cem grãos, tendo as massas variado de 21,6 a 35,8 gramas nos dois anos de cultivo.

Do total de genótipos estudados, 15 deles, o que corresponde a cerca de $60 \%$ apresentaram resposta positiva a adubação nitrogenada respondendo com o incremento na massa de grãos, sendo eles, CNFC-10467, CNFC-10406, BRS-Horizonte, IAC-Galante, BRS-Majestoso, Uirapuru, BRSMarfim, IPR-Colibri, IPR-Saracura, Safira, IPRCorujinha, IPR-Tiziu, IAC-Diplomata, Pérola e IPR-Gralha (Tabela 4). Em estudo com estresse mineral (nitrogênio) em feijoeiro no sul do Tocantins Salgado (2011) também obteve incrementos na massa de cem grãos, porém, somente $25 \%$ dos 12 genótipos avaliados apresentaram essa resposta positiva.

Para a característica produtividade de grãos nas condições do ambiente de baixo nível de nitrogênio, não foram observadas diferenças significativas entre os genótipos, tendo as produtividades variado de 82,59 a 365, $61 \mathrm{~kg} \cdot \mathrm{ha}^{-1}$. Em condições de alta dose de nitrogênio, a 
linhagem CNFC-10467 mostrou-se superior estatisticamente em relação aos demais genótipos, apresentando produtividade de 1.332,58 kg.ha ${ }^{-1}$ (Tabela 4). Estes resultados são inferiores aos encontrados por Lemos et al. (2004) que obtiveram rendimentos maiores, variando de 1.449 a $3623 \mathrm{~kg} \cdot \mathrm{ha}^{-1}$. Aférri et al. (2005) obtiveram rendimentos abaixo de $2000 \mathrm{~kg} \cdot \mathrm{ha}^{-1}$, semelhantes aos obtidos no presente estudo.

Os genótipos CNFC-10406 e BRS-Esplendor juntamente com CNFC-10467 foram os únicos genótipos a obterem rendimentos superiores a $1000 \mathrm{~kg} \cdot \mathrm{ha}^{-1}$, embora os dois primeiros tenham diferido estatisticamente da linhagem CNFC10467. Estes valores observados estão acima da média nacional e também da média do estado do Tocantins, que são de 885 e 1554 kg.ha-1, respectivamente, de acordo com estimativas para safra 11/12 (Conab, 2011). Porém, estes rendimentos são inferiores aos encontrados por Salgado et al. (2011) e Salgado (2011), que obtiveram com os rendimentos superiores, variação nas médias de 1.348 a $3.132 \mathrm{~kg} \cdot \mathrm{ha}^{-1}$.
Os genótipos CNFC-10467 e CNFC-10406 dentre as demais linhagens foram as que apresentaram melhores desempenhos, compondo quase sempre os grupos de maiores valores encontrados para cada característica avaliada, sendo muitas vezes superiores as cultivares comerciais. Estes resultados confirmam que a produtividade de grãos está correlacionada com o número de grãos por vagem e massa de cem grãos, variáveis que são de grande importância para seleção de genótipos produtivos (Lemos et al., 2004). Desta forma, tais genótipos demonstram potencial para originar cultivares comerciais para o cultivo na entressafra em condições de várzea irrigada no Estado do Tocantins.

Todos os genótipos avaliados apresentaram resposta positiva à adubação nitrogenada na produtividade, exceto o cultivar Pérola. Os incrementos obtidos variaram de 56,91 a $1.049 \%$. Salgado (2011) obteve acréscimos inferiores aos obtidos no presente trabalho, assim como a quantidade de genótipos que apresentaram esta resposta positiva à aplicação do adubo nitrogenado $(58 \%)$.

Tabela 4. Médias das características massa de cem grãos (MCG) e produtividade de grãos (PROD) de 25 genótipos de feijão comum cultivados em área de várzea irrigada do Estado de Tocantins, na entressafra de 2011.

\begin{tabular}{lcccccc}
\hline \multirow{2}{*}{ Genótipo } & \multicolumn{3}{c}{ MCG(g) } & \multicolumn{3}{c}{ PROD(kg.ha $\left.{ }^{-1}\right)$} \\
\cline { 2 - 6 } & Baixo N & Alto N & Média & Baixo N & Alto N & Média \\
\hline CNFC-10467 & $15,88 \mathrm{bB}$ & $26,76 \mathrm{aA}$ & 21,32 & $123,74 \mathrm{aB}$ & $1332,58 \mathrm{aA}$ & 728,16 \\
IAC-Una & $22,74 \mathrm{aA}$ & $22,91 \mathrm{bA}$ & 22,82 & $365,61 \mathrm{aB}$ & $957,39 \mathrm{bA}$ & 661,50 \\
CNFC-10406 & $19,89 \mathrm{aB}$ & $24,74 \mathrm{aA}$ & 22,31 & $192,63 \mathrm{aB}$ & $1040,70 \mathrm{bA}$ & 616,66 \\
BRS-Esplendor & $16,34 \mathrm{bA}$ & $17,21 \mathrm{cA}$ & 16,77 & $136,49 \mathrm{aB}$ & $1074,42 \mathrm{bA}$ & 605,46 \\
IPR-Chopin & $17,70 \mathrm{bA}$ & $20,39 \mathrm{cA}$ & 19,04 & $265,24 \mathrm{aB}$ & $926,36 \mathrm{bA}$ & 595,80 \\
BRS-Aporé & $20,29 \mathrm{aA}$ & $23,05 \mathrm{bA}$ & 21,67 & $240,14 \mathrm{aB}$ & $904,87 \mathrm{bA}$ & 572,50 \\
BRS-Horizonte & $22,64 \mathrm{aB}$ & $26,09 \mathrm{aA}$ & 24,37 & $172,13 \mathrm{aB}$ & $958,02 \mathrm{bA}$ & 565,08 \\
IAC-Galante & $20,84 \mathrm{aB}$ & $27,61 \mathrm{aA}$ & 24,23 & $186,67 \mathrm{aB}$ & $916,08 \mathrm{bA}$ & 551,37 \\
BRS-Majestoso & $20,05 \mathrm{aB}$ & $26,29 \mathrm{aA}$ & 23,17 & $183,91 \mathrm{aB}$ & $868,12 \mathrm{bA}$ & 526,02 \\
BRS-Grafite & $21,06 \mathrm{aA}$ & $23,12 \mathrm{bA}$ & 22,09 & $102,74 \mathrm{aB}$ & $946,89 \mathrm{bA}$ & 524,81 \\
VC3 & $20,48 \mathrm{aA}$ & $21,33 \mathrm{cA}$ & 20,90 & $112,65 \mathrm{aB}$ & $936,27 \mathrm{bA}$ & 524,46 \\
Uirapuru & $16,59 \mathrm{bB}$ & $24,14 \mathrm{aA}$ & 20,36 & $126,46 \mathrm{aB}$ & $916,63 \mathrm{bA}$ & 521,54 \\
BRS-Marfim & $20,20 \mathrm{aB}$ & $29,36 \mathrm{aA}$ & 24,78 & $82,59 \mathrm{aB}$ & $949,33 \mathrm{bA}$ & 515,96 \\
IPR-Colibri & $19,33 \mathrm{aB}$ & $23,64 \mathrm{bA}$ & 21,49 & $192,79 \mathrm{aB}$ & $813,74 \mathrm{bA}$ & 503,26 \\
IPR-Saracura & $21,67 \mathrm{aB}$ & $26,58 \mathrm{aA}$ & 24,12 & $277,0 \mathrm{aB}$ & $708,20 \mathrm{cA}$ & 492,60 \\
IAC-Eté & $17,79 \mathrm{bA}$ & $20,08 \mathrm{cA}$ & 18,93 & $150,30 \mathrm{aB}$ & $799,41 \mathrm{bA}$ & 474,86 \\
Safira & $14,47 \mathrm{bB}$ & $23,24 \mathrm{bA}$ & 18,85 & $207,05 \mathrm{aB}$ & $724,03 \mathrm{cA}$ & 465,54 \\
IPR-Corujinha & $20,90 \mathrm{aB}$ & $27,27 \mathrm{aA}$ & 24,08 & $198,93 \mathrm{aB}$ & $721,35 \mathrm{cA}$ & 460,14 \\
CNFC-10470 & $21,03 \mathrm{aA}$ & $24,30 \mathrm{aA}$ & 22,66 & $253,28 \mathrm{aB}$ & $646,82 \mathrm{cA}$ & 450,05 \\
IAC-Alvorada & $23,23 \mathrm{aA}$ & $25,63 \mathrm{aA}$ & 24,43 & $192,25 \mathrm{aB}$ & $707,00 \mathrm{cA}$ & 449,62 \\
IPR-Tiziu & $16,43 \mathrm{bB}$ & $22,89 \mathrm{bA}$ & 19,66 & $171,69 \mathrm{aB}$ & $674,22 \mathrm{cA}$ & 422,95 \\
IPR-139 & $23,48 \mathrm{aA}$ & $22,80 \mathrm{bA}$ & 23,14 & $270,58 \mathrm{aB}$ & $524,64 \mathrm{cA}$ & 397,61 \\
IAC-Diplomata & $18,55 \mathrm{bB}$ & $25,09 \mathrm{aA}$ & 21,82 & $166,83 \mathrm{aB}$ & $617,45 \mathrm{cA}$ & 392,14 \\
\end{tabular}




\begin{tabular}{lllcccc} 
Pérola & $21,45 \mathrm{aB}$ & $26,44 \mathrm{aA}$ & 23,95 & $279,05 \mathrm{aA}$ & $437,87 \mathrm{cA}$ & 358,46 \\
IPR-Gralha & $15,52 \mathrm{bB}$ & $20,64 \mathrm{cA}$ & 18,08 & $171,26 \mathrm{aB}$ & $458,84 \mathrm{cA}$ & 315,05 \\
\hline \multicolumn{1}{c}{ Média } & 19,54 & 24,07 & 192,88 & 822,45 \\
\hline
\end{tabular}

Médias seguidas de mesma letra minúscula na coluna não diferem entre si pelo teste Scott-Knott e maiúscula na linha pelo teste Tukey, ambos a $5 \%$ de probabilidade.

\section{CONCLUSÕES}

Os genótipos estudados apresentaram em condições de várzea irrigada altura de inserção da primeira vagem viável para colheita mecanizada. Os genótipos responderam à adubação nitrogenada, excetuando o cultivar Pérola.

O genótipo CNFC-10467 destacou-se obtendo a maior produtividade e sempre compondo os grupos de maiores valores para as características avaliadas, mostrando assim potencial para o cultivo em condições de várzea irrigada.

\section{RESUMO}

A cultura do feijoeiro apresenta enorme importância sócioeconômica para o Brasil e tem na adubação nitrogenada um dos fatores mais limitantes. Desta forma, objetivou-se com este estudo avaliar o efeito da adubação nitrogenada em genótipos de feijão comum cultivados em solos de várzea irrigada do Estado do Tocantins. O estudo foi conduzido em dois experimentos (alto e baixo nitrogênio) com delineamento em blocos casualizados, sendo avaliados 25 genótipos, em três repetições. As características avaliadas foram altura de inserção de primeira vagem, altura de planta, número de vagens por planta, número de grãos por vagem, massa de cem grãos e produtividade de grãos. Os genótipos estudados apresentaram aptidão para colheita mecanizada e também resposta positiva a adubação nitrogenada. $\mathrm{O}$ genótipo CNFC-10467 destacou-se apresentando potencial para o cultivo em áreas de várzea irrigada do Estado do Tocantins.

Palavras-chave: Phaseolus vulgaris, estresse mineral, subirrigação

\section{REFERÊNCIAS}

Afférri, F. S.; Oliveira, E. T. de; Silva, V. M. da; Gomes, M. P.; Almeida Júnior, D. (2005). Avaliação de cultivares e linhagens de feijão dos grupos comerciais carioca e preto, sob irrigação, no município de Gurupi-TO, no ano 2003. In: Anais, CONAFE, VIII Congresso Nacional de Pesquisa de Feijão. Santo Antônio de Goiás: Embrapa Arroz e Feijão.

Aidar, H. e KluthcouskI, J. (2008), Relatório de Atividades de Pesquisa com o Feijoeiro Comum nas Várzeas Tropicais do Tocantins: Adequações
Fitotécnicas com o Feijoeiro Cultivado em Sucessão ao Arroz Irrigado em Várzeas Tropicais. Santo Antônio de Goiás: Embrapa, (Documentos), 225, 40p.

Binotti, F. F. S.; Arf, O.; Sá, M. E.; Buzetti, S.; Alvarez, A. C. C.; Kamimura, K. M. (2009), Fontes, doses e modo de aplicação de nitrogênio em feijoeiro no sistema plantio direto. Bragantia, 68, 473-481.

Blum, A. 1988), Plant breeding for stress environments. Boca Raton: CRC Press.

Borém, A.; Carneiro, J. E. S. (2006), A cultura. In: Vieira, C.; Paula Júnior, T. J. de; Borém, A. (Ed.) Feijão. 2. Ed. Viçosa: Editora UFV, 19-40.

Camargo, F. A. O.; Silva, L. S.; Gianello, C.; Tedesco, M. J. (2008), Nitrogênio orgânico do solo. In: Santos, G. A.; Silva, L. S. S.; Canellas, L. P.; Camargo, F. A. O. (Ed.)., Fundamentos da matéria orgânica do solo: ecossistemas tropicais e subtropicais. Porto Alegre: Grafica Metropole, 87 $-99$.

Cardoso S. M.; Soratto R. P.; Silva A. H.; Mendonça C. G. (2011), Fontes e parcelamento do nitrogênio em cobertura, na cultura do milho sob plantio direto. Revista Brasileira de Ciências Agrárias, 6, 23-28.

Companhia Nacional de Abastecimento CONAB. (2011) Acompanhamento da safra brasileira: grãos. Disponível em: http://www.conab.gov.br/OlalaCMS/uploads/arqui vos/11_10_11_14_19_05_boletim_outubro2011.pdf. Acesso em: 28 de outubro de 2011.

EMBRAPA. (2006), Centro Nacional de Pesquisa de Solos, Sistema brasileiro de classificação de solos. 2. Ed. Brasília, Embrapa/Dpi. 306p.

Fageria, N. K. (1998), Eficiência de uso de fósforo pelos genótipos de feijão. Revista Brasileira de Engenharia Agrícola e Ambiental, 2, 128- 131. 
Fageria, N. K.; Santos, A. B .; Stone, L. F. (2003), Manejo de nitrogênio em arroz irrigado. Santo Antônio de Goiás: Embrapa, (Circular Técnica), 58, 4 p.

Fageria, N. K. e Baligar, V. C. (2005), Enhancing nitrogen use efficiency in crop plants. Advances in Agronomy, 88, 97-185.

Fageria, N. K.; Oliveira, I. P. de; Dutra, L. G. (1996), Deficiências nutricionais na cultura do feijoeiro e suas correções. Goiânia: EmbrapaCnpaf, (Documentos), 65, 40p.

Fageria, N. K. e Santos, A. B. (1998), Adubação fosfatada para o feijoeiro em solo de várzea. Revista Brasileira de Engenharia Agrícola $e$ Ambiental, 2, 124-127.

Ferreira, D. F. (2008), Sisvar: um programa para análises e ensino de estatística. Revista Symposium, 6, 36-41.

Fidelis, R. R.; Miranda, G. V.; Faluba, J. S. (2010), Capacidade de combinação de populações de milho tropicais sob estresse de baixo nitrogênio. Bioscience Journal, 26, 358-366.

Fidelis, R. R.; Miranda, G. V.; Erasmo, E. A. L. (2009), Seleção de populações base de milho sob alta e baixa dose de fósforo em solo de cerrado. Pesquisa agropecuária tropical, 39, 285-293.

Kischel, E.; Fidelis, R. R.; Santos, M. M.; Brandão, D. R.; Cancellier, E. L.; Nascimento, I. R. (2011), Efeito do nitrogênio em genótipos de arroz cultivados em várzea úmida do Estado do Tocantins. Revista Ceres, 58, 84-89.

Lemos, L. B.; Oliveira, R. S.; Palomino, E. C.; Silva, T. R. B. (2004), Características agronômicas e tecnológicas de genótipos de feijão do grupo comercial Carioca. Pesquisa Agropecuária Brasileira, 39, 319-326.

Mechi, R.; Brazaca, S. G. C.; Arthur, V. (2005), Avaliação química, nutricional e fatores antinutricionais do feijão preto (Phaseolus vulgaris 1.) irradiado. Ciência e Tecnologia de Alimentos, 25, 109-114.
Roselem, C. A. e Marubayashi, O. M. (1994), Seja doutor do seu feijoeiro. Botucatu: Potafos, (Arquivo do Agrônomo), 7, 18p.

Salgado, F. H. M. Efeito do nitrogênio na produtividade de grãos e qualidade fisiológica de sementes de genótipos de feijão comum. Dissertação (Mestrado em Produção Vegetal) Universidade Federal do Tocantins, 2011.

Salgado, F. H. M.; Fidelis, R. R.; Carvalho, G. L.; Santos, G. R.; Cancellier, E. L.; Silva, G. F. (2011), Comportamento de genótipos de feijão, no período da entressafra, no sul do estado de Tocantins. Bioscience Journal, 27, 52-58.

Sant'ana, E. V. P.; Santos, A. B.; Silveira, P. M. (2010), Adubação nitrogenada na produtividade, leitura spad e teor de nitrogênio em folhas de feijoeiro. Pesquisa Agropecuária Tropical, 40, 491-496.

Santos, A. B, Fageria, N. K, Silva, O. F.; Melo, M. L. B. (2003), Resposta do feijoeiro ao manejo de nitrogênio em várzeas tropicais. Pesquisa Agropecuária Brasileira, 38,1265-1271.

Santos, J. B.; Gavilannes, M. L.(2006). Botânica. In: Vieira, C.; Paula Júnior, T. J.; Borém, A. (Ed.). Feijão. 2.Ed. Viçosa: Universidade Federal de Viçosa, p. 41-65.

Santos, M. X.; Guimarães, P. E. O.; Pacheco, C. A. P.; Franca, G. E.; Nettoparentoni, S.; Gama, E. E. G.; Lopes, M. A. (1998), Melhoramento intrapopulacional no sintético elite NT para solos pobres em nitrogênio: I. Parâmetros genéticos de produção. Pesquisa Agropecuária Brasileira, 33, 55-61.

Silveira, G. M. (1991), As máquinas para colheita e transporte. São Paulo, Globo. 184p.

Simone, M.; Failde, V.; Garcia, S.; Panadero, P. C. (1992), Adaptación de variedades y líneas de judías secas (Phaseolus vulgaris L.) a La recolección mecânica directa. Salta: INTA. 5p.

Singh, B. B. (1982), Sixty-day cowpea varieties. Agronomy Abstracts, Madison,83p. 